\title{
Technological Experiments for the Enhancement of Glycerol Content in High Quality Wines
}

\author{
Cs. Csutorás ${ }^{1^{*}}$, O. Hudák ${ }^{1}$, K. Rácz ${ }^{2}$, L. Rácz ${ }^{1}$ \\ ${ }^{1}$ Institute of Food Science, Egerfood Regional Knowledge Center, Eszterhazy Karoly University, Eger, Hungary \\ ${ }^{2}$ Eger Crown Winehouse Ltd., Kerecsend, Hungary \\ Email: ${ }^{*}$ csuti@ektf.hu
}

Received December 2013

\begin{abstract}
The glycerol content of grape juices and wines has been determined by gas-chromatographic methods using silyl derivatives. The effect of different storage conditions and yeast cultures on glycerol content has been investigated. Grape juice samples with different starting D-Glucose concentrations have been treated with several additives $\left(\mathrm{HPO}_{4}{ }^{2-}, \mathrm{S}_{2} \mathrm{O}_{5}{ }^{2-}\right.$, NADH and $\left.\mathrm{HSO}_{3}{ }^{-}\right)$. Significant glycerol concentration enhancement has been detected in the case of the addition of NADH (5.14 $\mathrm{g} / \mathrm{L})$, however the presence of $\mathrm{HSO}_{3}{ }^{-}$prevented the excessive glycerol formation $(1.21 \mathrm{~g} / \mathrm{L})$.
\end{abstract}

\section{Keywords}

Glycerol; Wine Quality; Wine-Making Technology; Gas Chromatography

\section{Introduction}

Glycerol (propane-1,2,3-triol) belongs to a family of non-volatile polyalcohols and represents an important component of natural saponifiable lipids (e.g. esters formed with fatty acids). Pure glycerol is an odorless, colorless, high viscosity liquid. Several glycerol derivatives (e.g. dihydroxyacetone) play important role in essential biochemical metabolic processes, one of them is the glycolysis, where the six-carbon atom containing D-glucose is cleaved to dihydroxyacetone and glycerol aldehyde and finally to pyruvate with three carbon atoms. Since glycerol molecule is a closely related to these important decomposition products, it has important biological significance and appears as side product in several biological processes (alcoholic fermentation, aging and ripening of wines). Glycerol is involved in several microbiological or enzymatic transformation routes, the naturally bound glycerol is widespread in natural biological sources. Glycerol is widely used in the industry for the production of dye, paper, textile, fuel, cosmetics, medicine and food [1-5]. The chemical analysis of glycerol is important in clinical diagnostics as well, since the triacyl glyceride level in blood gives vital information concerning diseases of the cardiovascular system.

The biosynthesis of glycerol in cells is closely associated with osmotic cell regulation [6]. The anaerobic

${ }^{*}$ Corresponding author.

How to cite this paper: Csutorás, Cs., et al. (2014) Technological Experiments for the Enhancement of Glycerol Content in High Quality Wines. Journal of Agricultural Chemistry and Environment, 3, 48-52. 
conversion of glucose into ethanol by Saccharomyces cerevisiae is redox neutral. $\mathrm{NAD}^{+}$is consumed initially in the Embden-Meyerhof-Parnas (EMP) pathway that is regenerated during the production of ethanol. However, when intermediates in the EMP pathway are consumed as precursors for the synthesis of the cellular material, this balance will be disturbed, since the produced NADH is not converted back into NAD ${ }^{+}$. The shift in redox balance stops the metabolism of yeast cells, unless other processes are employed for the regeneration of NAD ${ }^{+}$. During the anaerobic growth of $S$. cerevisiae NADH cannot be oxidized by oxygen, but the conversion of $\mathrm{NADH}$ to $\mathrm{NAD}^{+}$can be achieved in the cell by the formation of reduced by-products such as glycerol. The production of glycerol in yeast cells is caused by the need to maintain a favorable redox balance [6-11] by the conversion of NADH that is formed during the biomass production, to $\mathrm{NAD}^{+}$. Glycerol formation requires the reduction of dihydroxyacetone phosphate to glycerol-3-phosphate (G-3-P) catalyzed by dihydroxyacetone phosphate reductase. In the process one molecule $\mathrm{NAD}^{+}$will be produced from NADH that was formed previously in the oxidation of glyceraldehyde-3-phosphate. The reaction is catalyzed by G-3-P dehydrogenase (GPDH) followed by the dephosphorylation of G-3-P to glycerol by glycerol-3-phosphatase [11]. Glycerol formation may serve in the cells as a route for the transformation of NADH to $\mathrm{NAD}^{+}$.

Summarizing the biochemical process, glycerol is formed in wines as a by-product of glycolysis of wine yeasts like S. cerevisiae during wine fermentation. The glycerol concentration in grape juice is low but during fermentation $4 \%-10 \%$ of the sugar content is converted into glycerol [12]. Glycerol concentration in wines varies between 1 and $10 \mathrm{~g} / \mathrm{L}[13,14]$, however red wines generally contain higher levels of glycerol than white wines. Glycerol does not have direct impact on wine flavor however it enhances the quality by improving physical properties like viscosity and smoothness. Nowadays there is a high demand on the production of wines with higher glycerol levels, since there is a close connection between quality and glycerol concentration [15]. The viscous liquid glycerol has sweet taste thus high concentrations of glycerol favorably influence the organoleptic evaluation and the viscosity of wine [16]. Several experiments have been carried out for the investigation of glycerol production during the fermentation of sugar-containing liquids. Enhanced glycerol production can be achieved by the application of several inorganic salts [17] or by adjusting the $\mathrm{pH}$ to 7 or above resulting in the reduction of dihydroxyacetone phosphate to glycerol-3-phosphate by NADH [18].

In EU countries direct addition of glycerol to enhance the quality of wine is prohibited. In our work we aimed at the search for chemical compounds that influence the redox equilibrium of the fermentation process to enhance the glycerol content in wine. We focused in our experiments on the application of additives that are authorized in EU countries.

\section{Materials and Methods}

All chemicals and reagents (glycerol, MSTFA, pyridine, NADH) were purchased from Sigma Aldrich, St. Louis, USA. Yeast strains were purchased from a local winery trader (Interker-Wine Ltd). The derivatization process was performed under water free conditions, $2 \mathrm{~mL}$ of wine or grape juice samples were freeze dried for 12 hours and the residue was dissolved in $2 \mathrm{~mL}$ of pyridine. $100 \mu \mathrm{L}$ of pyridine solution and $100 \mu \mathrm{L}$ of N-Methyl$\mathrm{N}$-(trimethylsilyl) trifluoroacetamide (MSTFA) were added and stirred for 15 minutes at room temperature to yield the trimethylsilyl derivative. The reaction was terminated and the excess derivatizing agent was decomposed by the addition of $5 \mathrm{~mL}$ water. $2 \mathrm{~mL}$ heptane was used to extract the derivatized glycerol, the heptane solution was used in gas-chromatographic analysis. GC analysis was performed on a Shimadzu GC 2010 instrument using a HP-5 MS column (30m, $0.25 \mu \mathrm{m}$ x $0.25 \mu \mathrm{m}) .1 \mu \mathrm{L}$ of heptane solution was injected, helium gas as carrier $(1 \mathrm{~mL} / \mathrm{min})$ was applied.

The injector temperature was $200^{\circ} \mathrm{C}$ and the initial temperature of $110^{\circ} \mathrm{C}$ was held for 4 minutes, then it was increased to $150^{\circ} \mathrm{C}$ with a speed of $4^{\circ} \mathrm{C} / \mathrm{min}$, the temperature was further increased to $250^{\circ} \mathrm{C}$ with $20^{\circ} \mathrm{C} / \mathrm{min}$ rate and it was held for 11 minutes at this temperature. The detector temperature was $250^{\circ} \mathrm{C}$ and the total measuring time was 30 minutes. The retention time of glycerol under these conditions was 8.07 minutes.

\section{Results and Discussion}

The effect of the addition of different additives as potassium metabisulfite, diammonium phosphate, ammonium bisulfite and NADH to grape juices with different sugar concentrations has been examined. Experiments were carried out at different temperatures, glycerol levels of grape juices and wines were measured by GC methods. Glycerol is a highly polar compound thus gas chromatographic analysis in free form is not possible due to its 
high boiling point. The sample preparation has been involved silyl derivative formation in order to lower the boiling point of glycerol.

The glycerol formation has been studied using several different grape juice and wine samples (Table 1 and Table 2). Analysis of samples was performed multiple times during the maturation of wines (5, 10 and 20 days) and studied the effect of additives at different fermentation temperatures $\left(8^{\circ} \mathrm{C}-30^{\circ} \mathrm{C}\right)$. In our experiments various yeast strains have been used (Fermol Chardonnay-I, Mycoferm CRU-88-II, Uvaferm Sacharomyces Cerevisiae-III, Sacharomyces Bayanus-IV). The initial glycerol content of grape juice was found to be $1.13 \mathrm{~g} / \mathrm{L}$.

As maturation progressed, significant concentration increase has been detected for all wine samples and for all different yeast strains. After 20 days the highest glycerol content $(4.12 \mathrm{~g} / \mathrm{L})$ was obtained in a sample that was stored at cellar temperature using Mycoferm CRU-88-II strain.

The results of the experiments with different yeasts are shown in Table 1. There is no significant difference in glycerol concentrations in the function of the applied yeast strains, the best results were obtained in all cases with Mycoferm CRU-88 yeast strains. Temperature however seems to be an important factor in glycerol formation during fermentation. Significant differences were observed in glycerol concentrations during and at the end of wine fermentation. Higher temperatures are not favorable in the point of view of glycerol formation thus they should be avoided aiming at the production of high quality wines. By the way at higher temperatures there would be a failure also in the appropriate aroma composition of wines. The best results in glycerol content of the produced wine were obtained at lower temperatures, however extremely low temperatures are not favorable, since fermentation slows down or even stops. The best results were achieved at cellar temperature $\left(13^{\circ} \mathrm{C}-14^{\circ} \mathrm{C}\right)$ where the highest glycerol concentrations were measured.

The effect on glycerol production of different additives used in enology- $\left(\mathrm{NH}_{4}\right)_{2} \mathrm{HPO}_{4}, \mathrm{~K}_{2} \mathrm{~S}_{2} \mathrm{O}_{5}, \mathrm{NADH}$, $\mathrm{NH}_{4} \mathrm{HSO}_{3}$ ) - has also been studied. The experiments were carried out at different D-Glucose levels (10, 20 and $40 \mathrm{~g} / \mathrm{L}$ ) by applying Mycoferm CRU-88 yeast culture (Table 2). The sugar content of grape juices is crucial in the production of good quality wines.

The applied high quality white grape juice contained sugar at a concentration of $210 \mathrm{~g} / \mathrm{L}$. The addition of extra amount of glucose to grape juice definitely increased the amount of glycerol in wine during fermentation which is an experimental proof of the fact that the sugar content of grape juices determines the quality of the produced wine.

Table 1. Effect of yeasts and temperature on the glycerol content of wines during fermentation.

\begin{tabular}{cccc}
\hline Wine samples $^{*}$ & & Glycerol content $(\mathrm{g} / \mathrm{L})$ & 20 days \\
\cline { 2 - 4 } R I & 5 days & 10 days & 3.12 \\
R II & 2.62 & 2.83 & 3.28 \\
R III & 2.76 & 2.92 & 3.15 \\
R IV & 2.57 & 2.72 & 3.21 \\
C I & 2.53 & 2.74 & 4.08 \\
C II & 3.12 & 3.29 & 4.12 \\
C III & 3.18 & 3.32 & 4.06 \\
C IV & 3.15 & 3.21 & 4.05 \\
$30^{\circ} \mathrm{C} \mathrm{I}$ & 3.13 & 3.24 & 3.43 \\
$30^{\circ} \mathrm{C} \mathrm{II}$ & 2.43 & 3.28 & 3.52 \\
$30^{\circ} \mathrm{C}$ III & 2.65 & 3.32 & 3.48 \\
$30^{\circ} \mathrm{C}$ IV & 2.37 & 3.38 & 3.43 \\
$8^{\circ} \mathrm{C} \mathrm{C} \mathrm{I}$ & 2.41 & 3.35 & 3.68 \\
$8^{\circ} \mathrm{C}$ II & 2.13 & 2.58 & 3.82 \\
$8^{\circ} \mathrm{C}$ III & 2.18 & 2.53 & 3.71 \\
$8^{\circ} \mathrm{C}$ IV & 2.11 & 2.45 & 3.75 \\
\hline
\end{tabular}

${ }^{*} \mathrm{R}=$ room temperature, $\mathrm{C}=$ cellar temperature $\left(13^{\circ} \mathrm{C}-14^{\circ} \mathrm{C}\right)$, I = Fermol Chardonnay, II = Mycoferm CRU-88, III = Uvaferm Sacharomyces Cerevisiae, IV = Sacharomyces Bayanus. 
Table 2. Effect of glucose and different grape juice additives on the glycerol content of wines during fermentation.

\begin{tabular}{|c|c|c|c|}
\hline \multirow{2}{*}{ Applied additives } & \multirow{2}{*}{ Sample } & \multicolumn{2}{|c|}{ Glycerol content (g/L) } \\
\hline & & 8 days & 60 days \\
\hline \multirow{4}{*}{ No additive } & Grape juice & 2.10 & 3.38 \\
\hline & Grape juice + 10 g/L D-glucose & 1.82 & 3.59 \\
\hline & Grape juice + 20 g/L D-Glucose & 2.18 & 3.65 \\
\hline & Grape juice + 40 g/L D-Glucose & 1.56 & 3.75 \\
\hline \multirow{4}{*}{$200 \mathrm{mg} / \mathrm{L}\left(\mathrm{NH}_{4}\right)_{2} \mathrm{HPO}_{4}$} & Grape juice & 1.96 & 4.04 \\
\hline & Grape juice + 10 g/L D-glucose & 2.08 & 4.17 \\
\hline & Grape juice + 20 g/L D-Glucose & 2.24 & 4.90 \\
\hline & Grape juice + 40 g/L D-Glucose & 1.93 & 4.35 \\
\hline \multirow{4}{*}{$200 \mathrm{mg} / \mathrm{L} \mathrm{K}_{2} \mathrm{~S}_{2} \mathrm{O}_{5}$} & Grape juice & 0.61 & 3.56 \\
\hline & Grape juice + 10 g/L D-glucose & 0.44 & 3.00 \\
\hline & Grape juice + 20 g/L D-Glucose & 0.21 & 3.87 \\
\hline & Grape juice + 40 g/L D-Glucose & 0.16 & 3.72 \\
\hline \multirow{4}{*}{$500 \mathrm{mg} / \mathrm{L} \mathrm{NADH}$} & Grape juice & 2.23 & 4.39 \\
\hline & Grape juice + 10 g/L D-glucose & 2.25 & 4.63 \\
\hline & Grape juice + 20 g/L D-Glucose & 2.41 & 4.56 \\
\hline & Grape juice + 40 g/L D-Glucose & 2.02 & 5.84 \\
\hline \multirow{4}{*}{$0.4 \mathrm{~mL} / \mathrm{L} 41 \% \mathrm{NH}_{4} \mathrm{HSO}_{3}$} & Grape juice & 0.19 & 1.52 \\
\hline & Grape juice + 10 g/L D-glucose & 0.17 & 1.09 \\
\hline & Grape juice + 20 g/L D-Glucose & 0.17 & 1.26 \\
\hline & Grape juice + 40 g/L D-Glucose & 0.16 & 1.21 \\
\hline
\end{tabular}

In Table 2, the results of our experiments on the investigation of the effect of different additives on the concentration of glycerol in the produced wine are also summarized. Potassium metabisulfite and ammonium bisulfite disturb the fermentation process that results in the formation of a lower amount of glycerol compared with the control experiment. In the case of ammonium bisulfite the hindrance of yeast strains was more significant.

The addition of NADH to grape juice resulted in significant increase of glycerol production of the yeast. The addition of NADH caused a shift in redox balance that is an outer stress for yeast cells. Yeast cells answer to the stress by producing glycerol to decrease the concentration of NADH.

Similar effect has been caused by the addition of diammonium phosphate resulting in the formation of higher levels of glycerol. The presence of ammonium ions is a suitable medium for amino acid production of the yeast cells. Amino acid biosynthesis results in the formation of NADH that induces yeast cells to produce glycerol. Glycerol production helps the yeast cells to make the appropriate redox balance of NADH and NAD ${ }^{+}$.

The fermentation and glycerol content of grape juices and wines has been studied under different conditions and yeast strains. Gas-chromatographic methods have been applied in the quantitative evaluation of the glycerol content of wines. The highest glycerol levels have been detected at decreased temperature $\left(8^{\circ} \mathrm{C}-14^{\circ} \mathrm{C}\right)$. The D-Glucose concentration affects the glycerol production during the fermentation. Significant decrease has been detected, when the grape juice was treated with $\mathrm{HSO}_{3}{ }^{2-}$ but the addition of NADH or diammonium phosphate can almost double the glycerol content of wines.

\section{Acknowledgements}

The authors thank the National Development Agency for financial support (TÁMOP-4.2.2.A-11/1/KONV2012-0008, TÁMOP-4.2.3-12 /1/KONV-2012-0025, GOP-1.1.1.-11-2011-0015).

\section{References}

[1] Novo, L.P., Gurgel, L.V.A., Marabezi, K. and Curvelo, A.A.S. (2011) Delignification of Sugarcane Bagasse Using Glycerol-Water Mixtures to Produce Pulps for Saccharification. Bioresource Technology, 102, 10040-10046. http://dx.doi.org/10.1016/j.biortech.2011.08.050 
[2] Melero, J.A., Vicente, G., Morales, G., Paniagua, M., Morales, G. and Muñoz, P. (2012) Etherification of BiodieselDerived Glycerol with Ethanol for Fuel Formulation over Sulfonic Modified Catalysts. Bioresource Technology, 103, 142-144. http://dx.doi.org/10.1016/j.biortech.2011.09.105

[3] Gómez-Hens, A. and Fernández-Romero, J.M. (2006) Analytical Methods for the Control of Liposomal Delivery Systems. Trends in Analytical Chemistry, 25, 167-178. http://dx.doi.org/10.1016/j.trac.2005.07.006

[4] Salehpour, S. and Dube, M.A. (2012) Towards the Sustainable Production of Higher-Molecular-Weight Polyglycerol. Macromolecular Chemistry and Physics, 212, 1284-1293. http://dx.doi.org/10.1002/macp.201100064

[5] Calderon, M., Quadir, M.A., Sharma, S.K. and Haag, R. (2010) Dendritic Polyglycerols for Biomedical Applications. Advanced Materials, 22, 190-218. http://dx.doi.org/10.1002/adma.200902144

[6] Zoecklein, W.B., Fugelsang, K.C., Gump, H.B. and Nury, S.F. (1995) Wine Analysis and Production. Chapman \&Hall, New York, 99-100.

[7] Oura, E. (1977) Reaction Products of Yeast Fermentations. Process Biochemistry, 12, 19-21.

[8] Gancedo, C. and Serrano, R. (1989) Energy-Yielding Metabolism. In Rose, A.H. and Harrison, J.S., Eds., The Yeasts, 2nd Edition, Vol. 3, Academic Press, London, 205-259.

[9] Nordstrom, K. (1968) Yeast Growth and Glycerol Formation II. Carbon and Redox Balances. Journal of the Institute of Brewing, 74, 429-432. http://dx.doi.org/10.1002/j.2050-0416.1968.tb03154.x

[10] van Dijken, J.P. and Scheffers, W.A. (1986) Redox Balances in the Metabolism of Sugars by Yeast. FEMS Microbiology Reviews, 32, 199-224. http://dx.doi.org/10.1111/j.1574-6968.1986.tb01194.x

[11] Boulton, R.B., Singleton, V.L., Bisson, L.F. and Kunkee, E.R. (1996) Principles and Practices of Winemaking. Chapman \& Hall, New York, 146-150. http://dx.doi.org/10.1007/978-1-4615-1781-8

[12] Radler, F. and Schütz, H. (1982) Glycerol Production of Various Strains of Sacharomyces. American Journal of Enology and Viticulture, 33, 36-40.

[13] Rankine, B.C. and Bridson, D.A. (1971) Glycerol in Australian Wines and Factors Influencing Its Formation. American Journal of Enology and Viticulture, 22, 6-12.

[14] Ough, C.S., Fong, D. and Amerine, M.A. (1972) Glycerol in Wine: Determination and Some Factors Affecting. American Journal of Enology and Viticulture, 23, 1-5.

[15] Balli, D., Flari, V., Sakellaraki, E., Schoina, V., Iconomopoulou, M., Bekatorou, A. and Kanellaki, M. (2003) Effect of Yeast Cell Immobilization and Temperature on Glycerol Content in Alcoholic Fermentation with Respect to Wine Making. Process Biochemistry, 39, 499-506. http://dx.doi.org/10.1016/S0032-9592(03)00133-X

[16] Noble, A.C. and Bursick, G.F. (1984) The Contribution of Glycerol to Perceived Viscosity and Sweetness in White Wine. American Journal of Enology and Viticulture, 35, 110-113.

[17] Rapin, J.D., Marison, I.W., Von Stockar, U. and Reilly, P.J. (1994) Glycerol Production by Yeast Fermentation of Whey Permeate. Enzyme Microbial Technology, 16, 143-150. http://dx.doi.org/10.1016/0141-0229(94)90077-9

[18] Wang, Z.X., Zhuge, J., Fang, H. and Prior, B.A. (2011) Glycerol Production by Microbial Fermentation: A Review. Biotechnology Advances, 19, 201-223. http://dx.doi.org/10.1016/S0734-9750(01)00060-X 